\title{
Assessing the influence of motivations and attitude on mobile social networking use
}

\author{
Silvia Sanz-Blas • Carla Ruiz-Mafé • \\ Jose Martí-Parreño • Asunción Hernández-Fernández
}

Published online: 13 February 2013

(C) International Network of Business and Management 2013

\begin{abstract}
Social media have become one of the strongest growing Web 2.0 services worldwide as they are a powerful tool for consumers to recommend products and services. The influence of social networking sites in purchase behaviour and their growing use by consumers justify the need to further study key drivers of users' behaviour. Although there is now a significant body of literature on the use of social networks from a computer, there is scant literature on their use from mobile devices. As media convergence is a reality nowadays, there is a need to know if consumers behave in the same way when a service is accessed from different platforms. The present work aims to analyse the relationships between motivations, attitude and frequency of mobile social networking. The hypotheses were tested on a sample of 146 young adolescent users of mobile social networks, using multiple linear regression analysis. Analysis of the results suggests that the main motivations for mobile social networking amongst adolescents are relaxation/entertainment and
\end{abstract}

Carla Ruiz-Mafé and José Marti-Parreño acknowledge the financial support of the research project of the Valencian Regional Government (Generalitat Valenciana) (GV/2011-009). This paper was awarded the best paper presented at the Luso-Spanish Conference, Lisbon 2012, by the International Network of Business and Management Journals (INBAM).

S. Sanz-Blas · C. Ruiz-Mafé $(\bowtie) \cdot$ A. Hernández-Fernández

Faculty of Economics, Department of Marketing, Universitat de València,

Avda. De los Naranjos s/n, 46022 Valencia, Spain

e-mail: carla.ruiz@uv.es

S. Sanz-Blas

e-mail: silvia.sanz@uv.es

A. Hernández-Fernández

e-mail: asuncion.hernandez@uv.es

J. Martí-Parreño

Department of marketing, Universidad Europea de Madrid, C/General Elio, 8,

46010 Valencia, Spain

e-mail: jose.marti@uem.es 
social/informativeness. Relaxation/entertainment motivations positively reinforce adolescents' attitudes towards mobile social networking, whereas socialisation/ informativeness motivations reinforce access frequency. This present study also highlights the importance of attitude. Managerial implications are provided.

Keywords Social networks - Mobile telephony - Use motivations - Attitude · Frequency of use $\cdot$ Teenagers

\section{Introduction}

Social networks, or social media, have become one of the strongest growing Web 2.0 services worldwide. They are also an emerging tool for marketing communications. To give one example, according to Socialbakers (2012), Facebook's student audience skews towards younger Internet users: $58 \%$ are 34 or younger, whilst only $6 \%$ are 55 or older. This exponential increase in the number of social media users has been accompanied by a growing interest on the part of advertisers in investing part of their marketing budgets in the medium. Thus, this year, advertising investment in social media is expected to total around 5,540 million dollars and rise to almost 10,000 million dollars in 2012 (eMarketer 2011).

Social networks like Facebook, Tuenti or Twitter have become virtual online spaces that consumers use to share their daily experiences, videos, photographs, real time messages or emails (amongst other content), with their family, friends and acquaintances, thereby improving social interaction (Hsiao 2011; Wang et al. 2010). Through these social networks, consumers can also access the information and experiences of not only their friends and acquaintances regarding the organisations, brands, products and services they come into contact with, but also the opinions of consumers anywhere in the world. Thus, these social media have become a powerful tool for consumers to recommend products and services. In fact, $70 \%$ of social media users recommend commercial brands and products (Zenith Media 2010).

Furthermore, mobile telephony is playing an increasingly important role as a platform for accessing these social networks. With around 5,900 million subscriptions and a global penetration rate of $87 \%$ (ITU 2012), mobile telephony has become the most ubiquitous of technologies, facilitating and favouring access to digital networks through mobile Internet. Mobile devices play a strategic role in access to Web 2.0 applications and services. Thus, a country like Spain, which is not one of the top 25 countries in broadband Internet connections, comes 22nd in the number of mobile broadband subscriptions with $55.7 \%$ of its population accessing mobile Internet (ITU 2012). Smartphones are playing an increasing role as a platform to access these social media in Spain. So, $23.1 \%$ of Internet users accessed social media through mobile phones in 2010, representing a $272 \%$ increase of such activity in the period 2009-2010 and a $320 \%$ increase if we focus on the younger audience. Mobile social media users play an active role accessing their online profiles on a daily (44\%) or a weekly basis (79\%) (Zenith Media 2011). Furthermore, $46 \%$ of Internet sites accessed by mobile in 2010 were social 
networks and one-third of mobile Internet users in Spain download applications and use social networks (TNS 2011).

The literature review shows that consumers' personal characteristics and use motivations are key factors in technology adoption behaviour (Davis 1989; Davis et al. 1989; Kuo and Yen 2009; Lu et al. 2009). In this work, we focus on analysis of the motivations of Spanish adolescents for accessing social networks from their mobile phones. These use motivations promote more positive attitudes to use and lead to more frequent use, which undoubtedly make them a focus of interest for research in this area. The framework chosen to study mobile social networking motivations is the Uses and Gratifications Theory (Anderson and Meyer 1975; Blumler 1979; Katz et al. 1974; Levy 1977; Massey 1995; Mcquail 1995; Perse 1986; Rubin 1977, 1979), one of the most influential theories in the study of mass communication media. It is worth noting that although the literature on the adoption of Web 2.0 services such as social networks is abundant (Shin 2010), few studies have analysed the motivations that influence consumer mobile social networking behaviour. This study offers data on mobile social networking in Spain which have not been studied before.

It should also be noted that few studies have been carried out on young adolescents. Various studies state that young consumers are the greatest technophiles, the first to adopt mobile services and to make more active use of the mobile phone (Conecta 2011; Zenith Media 2011). Many studies regard these young people as digital natives because technology is an essential determinant of who they are and what they are like (Conecta 2011). We also focused our research on teenagers because mobile phones are essential to many youth lifestyles and it has been noted that the improved capabilities of mobile phones as personal and portable multimedia devices have led mobile phones to become indispensable to young consumers, attracting marketers' attention (Grant and O'Donohoe 2007). Mobile phones have become integrated into young people's everyday lives and are used to connect and synchronise peer networks (Oksman and Raitiainen 2001; Skog 2002).

In view of the above, the aim of this present work is to analyse the relationships between mobile social networking motivations, attitude and frequency of usage. The work is divided into two parts. The first, theoretical part includes the literature review, the proposed working hypotheses and the methodology. The second part, based on an empirical study of 146 young mobile social network users, examines the motivations for using mobile social networks and their influence on user behaviour.

\section{Literature review}

Perceived benefits of social networking

Mobile social networks offer consumers a set of benefits which favour adoption, including entertainment, socialisation and the improvement of the user's status. These motivations can be studied in the framework of the Uses and gratifications Theory (Katz et al. 1974; McQuail 1995). The Uses and Gratifications Theory 
enables examination of the medium's functions from the consumer perspective to discover what the medium is used for (McQuail 1995) and, therefore, what needs and desires it is able to meet (Anderson and Meyer 1975). The basic premise of this approach then is that individuals expose themselves to the medium to satisfy a set of needs that motivate the audience to actively seek, in that medium, gratification of their specific needs (Anderson and Meyer 1975; Katz et al. 1974).

Despite furthering study of communication media, this approach initially had a series of problems or limitations (Anderson and Meyer 1975; Swanson 1977) since (i) the conceptual framework was not fully defined and could even include more than one discipline; (ii) the main concepts and terms lacked precision; (iii) the audience was considered an active user of the medium (always seeking an objective or a need); and (iv) it did not take into account the possible conditioning factors of the environment and personal and/or social factors. These problems or limitations have been gradually overcome and the approach has become one of the most influential theories in the study of communication. This theory has been applied to interactive media such as the Internet (Eighmey 1997; Eighmey and McCord 1998; Parker and Plank 2000; Stafford et al. 2004) and the mobile phone (Grant and O’Donohoe 2007; Leung and Wei 2000; Özcan and Kocak 2003; Wei et al. 2010).

According to Katz et al. (1974), by consuming messages, receivers seek to satisfy four types of needs: (i) social and personal integration related to reinforcing the features of their personality and their personal relations; (ii) evasion or escape in relation to the desire for fun and entertainment; (iii) cognitive needs associated with satisfying information needs; and (iv) affective-aesthetic needs, related to reinforcing emotional and pleasure experiences. Focusing on the area of the Internet, Stafford et al. (2004) identify three types of gratifications perceived by the audience: (i) content gratifications (provided by content: entertainment, information, etc.); (ii) gratifications associated to the process (navigation, experience with a new technology, etc.); and (iii) social gratifications (interpersonal communication and belonging to a social network). Rafaeli (1986) identifies a set of use motivations for online university bulletins associated with entertainment, recreation and fun. Subsequently, Eighmey (1997) and Eighmey and McCord (1998) studied commercial websites and identified the greatest navigation motivations as being personal importance, involvement with the information and value of the entertainment. Parker and Plank (2000) identified the need for company and socialisation, the need to learn and the need for relaxation and fun. Roy (2009) identifies six Internet use motivations: personal development, exhibition, ease of use, relaxation, job opportunities and global exchange of experiences.

The telephony has been found to involve intrinsic or social uses and gratifications (such as status, keeping in touch with family, overcoming loneliness, and entertainment or escapism) and instrumental or task-oriented uses (such as scheduling, ordering and reassurance), regardless of whether it is fixed or wireless. The study by Leung and Wei (1998) applies the Uses and gratifications Theory framework to the context of pagers and identifies an additional motivation over other studies concerning the need to be fashionable. That is why adopters of certain innovations see them as symbols of status and social identity, helping them to reinforce their belonging to a group. Social networks are both a socialisation tool 
and an expression of identity. Social networks enable users to share photographs, project or manage their desired self-image and keep up to date with the latest trends in their environment. Leung and Wei (2000) further identified mobility and immediate access as two unique gratifications for mobile phone use. Furthermore, studies focusing on social networks (Hennig-Thurau et al. 2004; Wang and Fesenmaier 2004) report that members of virtual communities participate to satisfy three types of needs: (i) functional needs (to carry out certain activities), (ii) social needs (willingness to provide help and support, exchange ideas, etc.), and (iii) psychological needs (belonging to a community, membership, etc.).

Social Capital Theory (Nahapiet and Ghoshal 1998) can also provide a theoretical framework for the satisfaction of consumer needs in online social networks as webbased opinion platforms can be regarded as collective groups of consumers who participate by exchanging information in exchange for covering certain needs for affection, gratitude, socialisation, status, etc. Users who participate in social networks can develop affective ties with other participants (Gruen et al. 2006) and this in turn influences their attitude. The exchange of information in social networks also modifies participants' attitudes (Soderlund and Rosegren 2007). Thus, Lee et al. (2008) consider that negative comments from other users influence participants' attitudes. The study by Hsu and Lu (2004) demonstrates that social factors influence attitude towards the use of online games. Leung and Wei (1998) posit that the need to be fashionable is another motivation to use social networks.

The need for information is another important motivation for using electronic services. In a marketing context, informativeness is defined as the extent to which the advertising media provide users with resourceful and helpful information (Chen and Wells 1999; Ducoffe 1996; Ko et al. 2005). In a mobile advertising context, informativeness can increase the perceived advertising value of mobile phones, leading to the formation of a favourable attitude (Bauer et al. 2005; Xu et al. 2009) and a positive attitude towards mobile advertising (Saadeghvaziri and Seyedjavadain 2011). Bauer et al. (2005) found that mobile advertising messages delivering high informative value lead to a positive attitude towards mobile advertisingwhich in turn, leads to the behavioural intention to use mobile advertising services. Tsang et al. (2004) also found informativeness positively correlated to overall attitude towards mobile advertising.

Bauer et al. (2005) found information needs-along with entertainment and social needs - to be a contributing factor of the overall perceived usefulness of mobile marketing, leading to a positive effect on attitude towards mobile marketing.

Also, according to the Uses and Gratifications Theory, individuals accept and interact daily with different technologies because of intrinsic and extrinsic motivations. Therefore, there is a set of consumers who use new technologies for motives other than utilitarian ones. In particular, they seek fun, escapism and spontaneity (Kim 2002; Mathwick et al. 2002). They seek subjective, personal values that are not associated with performing a specific task (Dholakia and Uusitalo 2002). This hedonic value increases when virtual environments stimulate consumer imagination. These hedonic motivations have also been found when using other mobile services (Ha et al. 2007; Nysveen et al. 2005a, b; Saadeghvaziri and Seyedjavadain 2011). Currently, mobile phones are increasing their capability to 
deliver entertainment through more technological advanced devices like smartphones. These smartphones allow consumers to not only download games and entertainment applications, but also play online with friends and acquaintances, thereby meeting entertainment and sociability needs (chats, groups, teams). Ubiquity allows consumers to play these casual mobile social games during short times, whilst waiting for their bus or during a coffee break. This is one of the causes that has led gaming to the mainstream as any owner of a mobile phone has his own portable gaming device.

The influence of perceived entertainment on attitude towards technology use has been compared in previous studies. Nysveen et al. (2005a, b) demonstrate the influence of perceived entertainment on men's attitude to the use of mobile chat services. Ha et al. (2007) also show that perceived entertainment influences attitude towards use of interactive games.

In view of the above, we posit the following hypotheses.

H1 Use motivations directly and positively influence attitude towards mobile social networking.

H2 Use motivations directly and positively influence the frequency of access to mobile social networks.

Attitude towards use

Attitude is an individual's positive or negative evaluation of a given object or behaviour (Ajzen 1991; Fishbein and Ajzen 1975) and includes feelings or affective responses. It refers to the individual's general willingness to engage in a given behaviour. This attitude is the result of individual beliefs concerning the behaviour, the results of that behaviour and the importance attached to such beliefs. Attitudes towards mobile applications and use of them to access social networks are not just the result of beliefs concerning the behaviour, but are also determined by other variables that act on the individual-medium relationship such as use motivations, the opinions of other users or experience (Baron et al. 2006; Nysveen et al. 2005a, b).

The social psychology literature clearly suggests that attitude has two components: affective and cognitive (Bagozzi and Burnkrant 1985; Chaiken and Stangor 1987; McGuire 1985; Weiss and Cropanzano 1996). The affective component in attitude refers to how much the person likes the object of his thoughts (McGuire 1985) and measures the degree of emotional attraction to the object. The cognitive component refers to the individual's specific beliefs about the object (Bagozzi and Burnkrant 1985) and consists of a value-based assessment, judgment, reception or perception of the object (Chaiken and Stangor 1987). The cognitive dimension of attitude directly influences the individual's use and adoption of information systems, whereas the affective dimension has to be treated as a result variable in itself.

The relationship between attitude and behaviour towards social networking has been evidenced in previous studies. Thus, for example, Moon and Kim (2001) show the significant influence of attitude on website use intention. Curras et al. (2011) also show that attitude has a mediator role between social network use motivations and repeated access to that social network. Therefore, 
H3 Attitude to mobile use as a platform for accessing social networks directly and positively influences frequency of access to mobile social networks.

\section{Methodology}

The data were gathered from a target public of adolescents who access social networks from their mobile devices. In total, a valid sample of 146 young adolescents was obtained. The sample was composed of $54.5 \%$ men and $45.6 \%$ women between the ages of 15 and 16 in the penultimate and final years of compulsory secondary education. The field work took place in July 2011.

Before collecting the data, the questionnaire was pretested on a sample of 35 adolescent mobile social network users to improve the way scale items were framed and avoid interpretation errors. The final scale for use motivations was the result of (1) adaptation of previous scales on uses and gratifications in the area of mobile telephony (Grant and O'Donohoe 2007; Leung and Wei 2000; Özcan and Kocak 2003; Wei et al. 2010) and (2) several focus groups that analysed user mobile social networking behaviour. Participants were adolescents, all smartphone owners, with different levels of familiarity with data services. Attitude towards mobile social networking was measured using an adaptation of a scale designed by Taylor and Todd (1995). Frequency of use reflected greater or lesser frequency of access to mobile social networks from the mobile phone.

In general, all respondents show a very positive attitude towards using the mobile as a platform for accessing social networks (4.2 out of 5) and a significant percentage of them $(82.5 \%)$ access mobile social networks very frequently. The respondents' preferred virtual social networks are Tuenti $(98.6 \%)$ and Facebook (75\%). The respondents access their favourite social network mainly to write and read comments (3.84 and 3.99, respectively), chat (4.19) and access the profiles of friends, acquaintances and class/workmates (3.84).

\section{Analysis of the results}

Mobile social networking motivations

To measure mobile social networks' usage motivations, interviewees were asked to score the importance they attached to each of the motivations on a 5 point Likert, where 1 equals 'not important at all' and 5 'very important'.

Table 1 shows that users access mobile social networks for hedonic and utilitarian motivations. Thus, access to mobile social networking allows them to escape boredom (4.02), pass the time (4.17), entertain themselves (4.28) and have fun (4.22) and also keep in touch (4.44) and chat to (4.61), greet (4.10), inform, maintain or improve relations with the people they are closest to and people they do not see very often (4.10). Therefore users find entertainment and social motivations in mobile social networking and thus reinforce social relationships with people around them. However, they do not agree that they access mobile networking to be 
Table 1 Motivations for mobile social network use

\begin{tabular}{ll}
\hline Use motivations & Average $(N=146)$ \\
\hline 1. To escape boredom & 4.02 \\
2. To contact/chat with my friends/acquaintances/relations & 4.61 \\
3. To notify, update friends/acquaintances/relations with the latest news & 4.00 \\
4. To pass the time & 4.17 \\
5. For entertainment & 4.28 \\
6. For fun & 4.22 \\
7. For relaxation & 3.80 \\
8. To maintain or improve relations with friends/acquaintances/relations & 4.10 \\
9. To feel closer, more involved in the lives of friends/acquaintances/relations & 3.64 \\
10. To keep in touch with people I do not see very often & 4.44 \\
11. So that others know that I care about them & 3.25 \\
12. To be always available for people who care about me & 3.54 \\
13. To greet friends/acquaintances/relations & 4.10 \\
14. To get to know new people & 3.01 \\
15. To be fashionable & 2.50 \\
16. To look stylish & 2.26 \\
17. To be up to date with the latest fashion & 2.25 \\
\hline
\end{tabular}

Table 2 KMO and Bartlett's test

\begin{tabular}{ll}
\hline $\begin{array}{l}\text { Kaiser-Meyer-Olkin measure } \\
\text { of sampling adequacy }\end{array}$ & 0.797 \\
Correlation matrix determinant & \\
Bartlett's sphericity test & 0.0004 \\
G.l. & 693.308 \\
Sig. & 136 \\
\end{tabular}

fashionable (2.50) or look stylish (2.26). Therefore, there are no fashionable/status motivations for mobile social networking (2.25).

Exploratory factorial analysis of mobile social networking motivations

The dimensions underlying the scale of mobile social network use motivations were identified by running a principal components factor analysis, after the appropriate tests to ensure that the data could be subjected to this type of analysis (see Table 2). Scale reliability was checked first, with the following results: (1) There was no need to eliminate items; (2) Cronbach's alpha was 0.88.

After applying factor analysis to the set of 17 variables, 3 factors were obtained which explain $61.5 \%$ of the variance. The condition required to retain a factor is that its eigen value be greater than 1 . The composition of the factors is shown in Table 3, having assigned the variables to the factors with loadings over 0.5 (following Hair et al. 1999). 
Table 3 Data on the rotated factor matrix for the three main factors

\begin{tabular}{|c|c|c|c|}
\hline Study variables & $\begin{array}{l}\text { Factor } \\
1\end{array}$ & $\begin{array}{l}\text { Factor } \\
2\end{array}$ & $\begin{array}{l}\text { Factor } \\
3\end{array}$ \\
\hline 1. To escape boredom & 0.655 & & \\
\hline 2. To contact/chat with my friends/acquaintances/relations & & 0.87 & \\
\hline 3. To notify, update friends/acquaintances/relations with the latest news & & 0.537 & \\
\hline 4. To pass the time & 0.724 & & \\
\hline 5. For entertainment & 0.764 & & \\
\hline 6. For fun & 0.689 & & \\
\hline 7. For relaxation & 0.792 & & \\
\hline 8. To maintain or improve relations with friends/acquaintances/relations & & 0.561 & \\
\hline $\begin{array}{l}\text { 9. To feel closer, more involved in the lives of friends/acquaintances/ } \\
\text { relations }\end{array}$ & & 0.622 & \\
\hline 10. To keep in touch with people I do not see very often & & 0.739 & \\
\hline 11. So that others know that I care about them & & 0.637 & \\
\hline 12. To be always available for people who care about me & & 0.610 & \\
\hline 13. To greet friends/acquaintances/relations & & 0.740 & \\
\hline 14. To get to know new people & & 0.746 & \\
\hline 15. To be fashionable & & & 0.791 \\
\hline 16. To look stylish & & & 0.819 \\
\hline 17. To be up to date with the latest fashion & & & 0.757 \\
\hline Cronbach's alpha for each factor & 0.82 & 0.83 & 0.86 \\
\hline
\end{tabular}

The first factor, called relax/entertainment, explains $21.95 \%$ of the variance and comprises the following variables: escape boredom; pass the time; entertain myself; have fun and relax.

The second factor, called sociability/information, explains $21.04 \%$ of the variance and is made up of the following variables: keep in touch/chat with friends/ acquaintances/relations; find out about/tell update myself/update friends/acquaintances/relations about the latest news; maintain or improve relations with friends/ acquaintances/relations; feel closer to, more involved in the life of friends/ acquaintances/relations; keep in touch with people I do not see very often; so others know that I care about them; be always available for the people who care about me; greet friends/acquaintances/relations; meet new people.

The third factor, with the name fashion/status, explains $18.48 \%$ of the variance and reflects the following variables: be fashionable; look stylish; be up to date with the latest fashion.

These three factors coincide with the three dimensions that the authors established a priori on the basis of the literature review.

\section{Measurement instrument validation}

Reliability and validity of the use motivations scale were verified using confirmatory factor analysis taking into account the dimensions identified in the literature which coincide with our prior exploratory analysis. 
Table 4 Confirmatory factorial analysis of mobile social networking motivations scale

\begin{tabular}{llllllll}
\hline Dimension & Indicator & Load & Robust $\mathrm{t}$ & $\begin{array}{l}\text { Average } \\
\text { loads }\end{array}$ & $\begin{array}{l}\alpha \text { of } \\
\text { Cronbach }\end{array}$ & $\begin{array}{l}\text { Composed } \\
\text { reliability }\end{array}$ & AVE \\
\hline Relaxation/ & MOT1 & 0.542 & 4.116 & 0.67 & 0.82 & 0.81 & 0.49 \\
& MOT4 & 0.713 & 3.842 & & & & \\
& MOT5 & 0.572 & 4.182 & & & & \\
& MOT6 & 0.758 & 6.689 & & & & \\
Sociability & MOT7 & 0.803 & 5.408 & & & & \\
Informativeness & MOT2 & 0.821 & 7.279 & 0.67 & 0.87 & 0.86 & \\
& MOT3 & 0.664 & 8.092 & & & & \\
& MOT8 & 0.650 & 5.286 & & & & \\
& MOT9 & 0.626 & 7.098 & & & & \\
& MOT10 & 0.703 & 4.657 & & & & \\
& MOT12 & 0.507 & 3.966 & & & & \\
Fashion/status & MOT13 & 0.766 & 8.165 & & & & \\
& MOT15 & 0.844 & 8.697 & 0.80 & 0.86 & 0.84 & \\
& MOT16 & 0.739 & 6.479 & & & & \\
& MOT17 & 0.836 & 8.194 & & & & \\
\hline
\end{tabular}

$\mathrm{S}-\mathrm{B} \chi^{2}(d f=85)=114.622(p=0.017) ; \mathrm{NFI}=0.903 ; \mathrm{NNFI}=0.916 ; \mathrm{CFI}=0.935 ; \mathrm{IFI}=0.935$; RMSEA $=0.058$

Table 5 Discriminant validity on mobile social networking motivations scale

\begin{tabular}{lccc}
\hline & 1 & 2 & 3 \\
\hline 1. Relaxation/entertainment & $\mathbf{0 . 4 9}$ & 0.44 & 0.19 \\
2. Sociability/informativeness & {$[58 ; 74]$} & $\mathbf{0 . 4 9}$ & 0.20 \\
3. Fashion/status & {$[26 ; 55]$} & {$[19 ; 48]$} & $\mathbf{0 . 6 5}$
\end{tabular}

The diagonal (values in bold) represents the average variance extracted (AVE). Above the diagonal is the variance shared by each pair of factors (squared correlation). Below the diagonal is the $95 \%$ confidence interval for the inter-factor correlation

The results show that all the indicators, except MOT11 and MOT14, show significant factorial loads above 0.5 (Hair et al. 1999). These two items were eliminated to ensure convergent validity. The measurement model also showed good fit (see Table 4).

Internal consistency was measured with Cronbach's alpha and other complementary measures such as composed reliability and variance extracted. Both indicators showed values very close to or above the minimum threshold $(0.7$ and 0.5, respectively) (Hair et al. 1999).

Discriminant validity was evaluated following two criteria (see Table 5). Firstly, it was found that none of the confidence intervals at $95 \%$ for the estimations of correlations between each pair of factors contained the value 1 (Anderson and Gerbing 1988). Secondly, the variance shared between each pair of constructs (squared correlation) was below the corresponding variance extracted indexes (Fornell and Larcker 1981). 
Table 6 Regression analysis of use motivational factors to attitude to mobile social networks

\begin{tabular}{llll}
\hline Purchase motivations factors & Standardised $\beta$ coefficient & $T$ value & Sig. \\
\hline Constant & & 3.111 & 0.003 \\
Factor 1: relax/entertainment & $0.361^{* *}$ & 2.928 & 0.004 \\
Factor 2: sociability/information & $0.261^{* *}$ & 2.725 & 0.042 \\
Factor 3: fashion/status & 0.046 & 0.424 & 0.673 \\
\hline
\end{tabular}

Source produced with SPSS v. 17.0. Stepwise regression analysis

$R^{2}: 0.69$; adjusted $R^{2}: 0.49$

Durbin Watson $=1.589 ; F=10,473$ (Sig. $F=0.000)$

$* * p<0.01$

Influence of use motivations on attitude towards mobile social networks

After determining the main components or factors and having accepted the reliability of the underlying scales, their potential effects on attitude to mobile social networks were determined through multiple linear regressions (see Table 6). This analysis was carried out using the stepwise method, with attitude towards mobile social networks as the dependent variable and the different factors or components previously obtained in the exploratory factor analysis as explanatory variables.

The results show (see Table 6) that two of the three factors analysed have a positive and statistically significant effect $(p<0.05)$ on attitude to the use of mobile social networks.

The factor with the greatest influence on attitude is relax/entertainment, and the second most important factor is sociability/information. The factor fashion/status was not found to be significant. These variables are largely able to explain attitude to mobile social network use as the adjusted $R^{2}$ represents almost $50 \%$.

Influence of use motivations and attitude on mobile social networking frequency

In order to analyse the effect of mobile social network motivations on frequency of social network use, a multiple linear regression analysis was run again with frequency of mobile social network use as the dependent variable (see Table 7).

Table 7 Regression analysis of the use motivation factors to frequency of mobile social network use

\begin{tabular}{lllr}
\hline Purchase motivations factors & Standardized $\beta$ coefficient & T value & Sig. \\
\hline Constant & & 3.816 & 0.000 \\
Factor 1: relax/entertainment & $0.203^{*}$ & 2.013 & 0.045 \\
Factor 2: sociability/information & $0.287^{*}$ & 2.493 & 0.014 \\
Factor 3: fashion/status & 0.049 & 0.501 & 0.617 \\
\hline
\end{tabular}

Source produced with SPSS v. 17.0. Stepwise regression analysis

$R^{2}$ : 0.35 ; adjusted $R^{2}: 0.29$

Durbin Watson $=1.939 ; F=8.505$ (Sig. $F=0.000)$

$* p<0.05$ 
The results show again differences in the factors that are most significant for explaining the frequency of mobile social network use (see Table 7). Whilst fashion/status motivations are irrelevant for explaining use behaviour, relax/ entertainment and socialisation/information are important factors. In this case, socialisation/information is the most relevant factor, followed by relax/entertainment. The value of adjusted $R^{2}$ is not too high, which indicates that use behaviour may be influenced by other factors not related to use gratifications such as personal factors and socio-demographic or attitudinal variables.

\section{Conclusions and management implications}

The influence of social networks in interpersonal relations and their growing use by consumers justify the need to continue studying use behaviour. Although there is now a significant body of literature on the use of social networks from a computer, there is scant literature on their use from mobile devices. Media convergence is a reality nowadays and there is a need to know if consumers behave in the same way when a service is accessed from different platforms. The sacrifice of using a limited interface such as that of the mobile phone (as opposed to a desktop computer) can be recompensed by the immediacy and ubiquity offered by a mobile platform. Furthermore, few academic studies have used a sample of young adolescents. Various studies state that young people are the most technophile, the first to adopt mobile services and the ones that make more active use of the mobile phone (Conecta 2011; Zenith Media 2011) Many of these young people are also considered to be digital natives in many studies, as technology is an essential determinant of who they are and what they are like (Conecta 2011).

The results of this study show that young people access social networks much more frequently from their mobile, and that Tuenti is their favourite network. Their attitude towards the use of the mobile as a platform for accessing these social networks is very positive and it has become a channel for them to maintain and reinforce social relations with other people. As a result, young people mainly access the network to write and read comments from friends, acquaintances, family members or class/work mates and to chat.

Adolescents use mobile social networks mainly for relaxation/entertainment and social/informativeness motivations. The importance of these motivations is also evident from analysis of their impact on attitude towards mobile social networking and frequency of use. Thus, relaxation/entertainment motivations positively reinforce adolescents' attitudes towards mobile social networking, whereas socialisation/informativeness motivations encourage more frequent access.

The present study also shows the importance of attitude in the context of mobile social networks. The results indicate that attitude towards mobile social networking has a direct, significant influence on the frequency of use of that social network. Thus, individual loyalty to a network can be achieved if the individual shows a favourable attitude to using it.

The results provide a set of managerial implications. Firstly, companies that want a presence in social networks must know their target public very well (their tastes, 
needs and wants) in order to send personalised communications adapted to their needs and wants, providing them greater usefulness.

It is not just important to identify the public correctly, but they must also offer contents that match the motivations for using the application. Thus, communication must be fun and entertaining and, whenever possible, allow a certain amount of interactivity because when a person uses the terminal/application, they are seeking not only information, but also entertainment and social interaction. All of this will undoubtedly require greater efforts in creativity due to the limitations of the medium.

Given that attitudes also play a significant role in the use of a social network, companies must continue to reinforce them so that people will access the networks more frequently. In the case of mobile social networks, this could be achieved by reinforcing perceived entertainment of the network, making the information search and exchange convenient for the individual and by working on aspects of profile design. It is important to adapt the profile to the mobile medium, making it easy to participate and locate content and comments. In addition to text, images, photographs and videos must be offered to arouse users' interest and provide them with fun and entertainment.

Amongst the limitations of this study is the fact that only a collective of young adolescents has been analysed and that might condition the results. Another limitation is the very speed of change in the study area which restricts the validity of the findings to a given moment in time, as users' increased experience with the medium affects their behaviour.

As future lines of investigation, we propose replicating the study with a sample of young adults (25-39) to compare the results. It would also be interesting to compare our results with fixed terminal social networking behaviour to examine for any variation in use motivations. Another possible future research line would be to extend the proposed model by incorporating possible risks of mobile social networking (privacy, psychological, time wasting and social).

Acknowledgements The authors acknowledge the financial support of the research project of the Valencian Regional Government (Generalitat Valenciana) (GV/2011-009). This paper was awarded the best paper presented at the Luso-Spanish Conference, Lisbon 2012, by the International Network of Business and Management Journals (INBAM).

\section{References}

Ajzen, I. (1991). The theory of planned behavior. Organizational Behavior and Human Decision Processes, 50(2), 179-211.

Anderson, J. C., \& Gerbing, D. W. (1988). Structural equation modelling in practice: A review and recommended two-step approach. Psychological Bulletin, 103, 411-423.

Anderson, J. A., \& Meyer, T. P. (1975). Functionalism and the mass media. Journal of Broadcasting, 19(1), 11-22.

Bagozzi, R. P., \& Burnkrant, R. E. (1985). Attitude organization and the attitude-behavior relationship: A reply to Dillon and Kumar. Journal of Personality and Social Psychology, 49, 1-16.

Baron, S., Patterson, A., \& Harris, K. (2006). Beyond technology acceptance: understanding consumer practice. International Journal of Service Industry Management, 17(2), 111-135.

Bauer, H. H., Barnes, S. J., Reichardt, T., \& Neumann, M. M. (2005). Driving consumer acceptance of mobile marketing: A theoretical framework and empirical study. Journal of Electronic Commerce Research, 6(3), 181-191. 
Blumler, J. G. (1979). The role of theory in uses and gratifications studies. Communication Research, $6(1), 9-36$.

Chaiken, S., \& Stangor, C. (1987). Attitudes and attitude change. Annual Review of Psychology, 38, 575-630.

Chen, Q., \& Wells, W. D. (1999). Attitude toward the Site. Journal of Advertising Research, 39(5), 27-38.

Conecta (2011). $7^{\circ}$ Observatorio de tendencias NOKIA: los jóvenes, los móviles y la tecnología. http:// www.conectarc.com/Articulos\%20y\%20Estudios/Highlights\%206\%BA\%20Observatorio\%20Final. pdf.

Curras, R., Ruiz, C., \& Sanz, S. (2011). Antecedentes y consecuencias de la actitud hacia el uso de las redes sociales. Castellón: XXIII Congreso Nacional de Marketing.

Davis, F. D. (1989). Perceived usefulness, perceived ease of use, and user acceptance of information technology. MIS Quarterly, 13(3), 319-340.

Davis, F. D., Bagozzi, R. P., \& Warshaw, P. R. (1989). User acceptance of computer technology: A comparison of two theoretical models. Management Science, 35(8), 982-1003.

Dholakia, R., \& Uusitalo, O. (2002). Switching to electronic stores: Consumer characteristics and the perception of shopping benefits. International Journal of Retail and Distribution Management, 30(10), 459-469.

Ducoffe, R. H. (1996). Advertising value and advertising on the web. Journal of Advertising Research, 36(September-October), 21-35.

Eighmey, J. (1997). Profiling user responses to commercial web sites. Journal of Advertising Research, 37(Mayo/Junio), 59-66.

Eighmey, J., \& McCord, L. (1998). Adding value in the information age: uses and gratifications of sites on the World Wide Web. Journal of Business Research, 41, 187-194.

eMarketer (2011). Social Network Ad Revenues to Reach \$10 Billion Worldwide in 2013, October, 5th. http://www.emarketer.com/Article.aspx?R=1008625.

Fishbein, M., \& Ajzen, I. (1975). Belief, attitude, intention and behavior: an introduction to theory and research. Nueva York: Addison-Wesley.

Fornell, C., \& Larcker, D. F. (1981). Evaluating structural equations models with unobservable variables and measurement error. Journal of Marketing Research, 18(1), 39-50.

Grant, I., \& O'Donohoe, S. (2007). Why young consumers are not open to mobile marketing communication. International Journal of Advertising, 26(2), 223-246.

Gruen, T. W., Osmonbekov, T., \& Czaplewski, A. J. (2006). eWOM: The impact of customerto-customer online know-how exchange on customer value and loyalty. Journal of Business Research, 59(4), 449-456.

Ha, I., Yoon, Y., \& Choi, M. (2007). Determinants of adoption of mobile games under mobile broadband wireless access environment. Information and Management, 44(3), 276-286.

Hair, J. F., Anderson, R. E., Tatham, R. L., \& Black, W. C. (1999). Análisis multivariante. Madrid: Prentice Hall Iberia.

Hennig-Thurau, T., Gwinner, K. P., Walsh, G., \& Gremler, D. (2004). Electronic word-of-mouth via consumer-opinion platforms: what motivates consumers to articulate themselves on the internet. Journal of Interactive Marketing, 18(1), 38-52.

Hsiao, (2011). Why internet users are willing to pay for social networking services? Online Information Review, 35(5), 770-788.

Hsu, C. H., \& Lu, H. P. (2004). Why do people play on-line games? An extended TAM with social influences and flow experience. Information and Management, 41(7), 853-868.

ITU (International Telecommunication Union) (2012). Key 2000-2011 country data. http://www.itu.int/ ITU-D/ict/material/FactsFigures2012.pdf.

Katz, E., Blumler, J. G., \& Gurevitch, M. (1974). Utilization of mass communication by the individual. In J. G. Blumler \& E. Katz (Eds.), The uses of mass communication: Current perspective on gratifications research (pp. 19-34). Calif Sage: Beverly Hills.

Kim, Y.-K. (2002). Consumer value: An application to mall and internet shopping. International Journal of Retail and Distribution Management, 30(12), 595-602.

Ko, H., Cho, C.-H., \& Roberts, S. M. (2005). Internet uses and gratifications: A structural equation model of advertising. Journal of Advertising, 34(2), 57-70.

Kuo, Y., \& Yen, S. (2009). Towards an understanding of the behavioural intention to use 3G mobilevalue-added services. Computers in Human Behaviour, 1(25), 103-110. 
Lee, J., Park, D.-H., \& Han, I. (2008). The effect of negative online consumer reviews on product attitude: An information processing view. Electronic Commerce Research and Applications, 7(3), 341-352.

Leung, L., \& Wei, R. (1998). The gratifications of pager use: sociability, information-seeking, entertainment, usefulness and fashion and status. Telematics and Informatics, 15, 253-264.

Leung, L., \& Wei, R. (2000). More than just talk on the move: uses and gratifications of the cellular phone. Journalism and Mass Communications Quarterly, 77(2), 308-320.

Levy, M. R. (1977). Experiencing television news. Journal of Communication, 27(4), 112-117.

Lu, Y., Tao, Z., \& Wang, B. (2009). Exploring Chinese users' acceptance of instant messaging using the theory of planned behavior, the technology acceptance model and the flow theory. Computers in Human Behaviour, 25, 29-39.

Massey, K. B. (1995). Analyzing the uses and gratifications concept of audience activity with a qualitative approach: Media encounters during the 1989 Loma Prieta earthquake disaster. Journal of Broadcasting and Electronic Media, 39(3), 328-345.

Mathwick, C. H., Malhotra, N., \& Rigdon, E. (2002). The effect of dynamic retail experiences on experiential perceptions of value: an Internet and catalog comparison. Journal of Retailing, 78(1), 51-60.

McGuire, W. J. (1985). Attitudes and attitude change. In G. Lindzey \& E. Aronson (Eds.), Handbook of social psychology (Vol. 19, pp. 233-346). New York: Random House.

McQuail, D. (1995). Mass communication theory. Newbury Park: Sage.

Media, Zenith. (2010). Panorama de medios en españa 2009. Madrid: Zenith Media.

Moon, J., \& Kim, Y. (2001). Extending the TAM for a world-wide-web context. Information and Management, 38(4), 217-230.

Nahapiet, J., \& Ghoshal, S. (1998). Social capital, intellectual capital, and the organizational advantage. Academy of Management Review, 23(2), 242-266.

Nysveen, H., Pedersen, P. E., \& Thorbjornsen, H. (2005a). Explaining intention to use mobile chat services: Moderating effects of gender. Journal of Consumer Marketing, 22(5), 247-256.

Nysveen, H., Pedersen, P. E., \& Thorbjornsen, H. (2005b). Intentions to use mobile services: antecedents and cross-service comparisons. Academy of Marketing Science Journal, 33(3), 330-346.

Oksman, V. \& Raitiainen, T. (2001). Perhaps it is a body part. How the mobile phone became an organic part of everyday lives of children and teenagers, Nodiskakonferensenförmedie-ockkommunikationfiorskning, (pp 11-13) Island: Agosto.

Özcan, Y. Z., \& Kocak, A. (2003). A need or a status symbol?: Uses of cellular telephone in Turkey. European Journal of Communication, 18(2), 241-254.

Parker, B., \& Plank, R. (2000). A uses and gratifications perspective on the Internet: As a new information source. American Business Review, 18(june), 43-49.

Perse, E. M. (1986). Soap opera viewing patterns of college students and cultivation. Journal of Broadcasting and Electronic Media, 30(2), 175-193.

Rafaeli, S. (1986). The electronic bulletin board. A computer-driven mass-medium, in Computers and the Social sciences (Vol. 2, pp. 123-131). Florida: Paradigm Press.

Roy, S. (2009). Internet uses and gratifications. A survey in the Indian context. Computers in Human Behaviour, 25(4), 878-886.

Rubin, A. M. (1977). Television usage, attitudes and viewing behaviors of children and adolescents. Journal of Broadcasting, 21(3), 355-369.

Rubin, A. M. (1979). Television use by children and adolescents. Human Communication Research, 5(2), 109-120.

Saadeghvaziri, F., \& Seyedjavadain, S. (2011). Attitude toward advertising: Mobile advertising vs advertising-in-general. European Journal of Economics, Finance and Administrative Sciences, 28, $104-114$.

Shin, D. (2010). Analysis of online social networks: a cross-national study. Online Information Review, 34(3), 473-495.

Skog, B. (2002). Mobiles and the Norwegian teen: identity, gender and class. In J. E. Katz \& M. Aakhus (Eds.), Perpetual contact. New York: Cambridge University Press.

Socialbakers (2012). http://www.socialbakers.com/facebook-statistics/spain/last-6-months. Accessed 12 April 2012.

Soderlund, M., \& Rosegren, S. (2007). Receiving word-of-mouth from the service customer. An emotionbased effectiveness assessment. Journal of Retailing and Consumer Services, 14(2), 123-136.

Stafford, T., Stafford, M., \& Schkade, L. (2004). Determining uses and gratifications for the Internet. Decision Sciences, 35(2), 259-288. 
Swanson, D. L. (1977). The use and misuses of uses and gratifications. Human Communication Research, 3(3), 214-221.

Taylor, S., \& Todd, P. (1995). Understanding information technology usage: a test of competing models. Information Systems Research, 6(2), 144-176.

TNS (2011). Mobile life 2011. http://www.tnsglobal.com/research/key-insight-reports/D030D54689 03455DA353587691807B5C.aspx

Tsang, M. M., Ho, S.-C., \& Liang, T. P. (2004). Consumer attitudes toward mobile advertising: An empirical study. International Journal of Electronic Commerce, 8(3), 65-78.

Wang, Y., \& Fesenmaier, D. R. (2004). Modelling participation in an online travel community. Journal of Travel Research, 42(3), 261-270.

Wang, S., Moon, S., Kwon, K., Evans, C., \& Stefanone, M. (2010). Face off: Implications of visual cues on initiating friendship of Facebook. Computers in Human Behavior, 26(2), 226-234.

Wei, R., Xiaoming, H., \& Pan, J. (2010). Examining user behavioural response to SMS ads: implications for the evolution of the mobile phone as a bona-fide medium. Telematics and Informatics, 27(1), $32-41$.

Weiss, H. M., \& Cropanzano, R. (1996). Affective events theory: A theoretical discussion of the structure, causes and consequences of affective experiences at work. In B. M. Staw \& L. L. Cummings (Eds.), Research in organizational behavior (pp. 1-74). Greenwich: JAI Press.

Xu, H., Oh, L.-B., \& Teo, H.-H. (2009). Perceived effectiveness of text vs. multimedia location-based advertising messaging. International Journal of Mobile Communication, 7(2), 154-177.

Zenith Media. (2011). Móviles y publicidad. Percepciones, usos y tendencias. Madrid: Zenith Optimedia Group. 